\title{
Curcumin inhibits intracellular fatty acid synthase and induces apoptosis in human breast cancer MDA-MB-231 cells
}

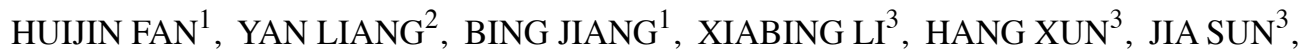 \\ WEI HE ${ }^{4}$, HAY TONG LAU ${ }^{4}$ and XIAOFENG MA ${ }^{1}$ \\ ${ }^{1}$ College of Life Sciences, University of Chinese Academy of Sciences, Beijing 100049; ${ }^{2}$ School of Kinesiology \\ and Health, Capital University of Physical Education and Sports, Beijing 100191; ${ }^{3}$ State Forestry Administration, \\ International Centre for Bamboo and Rattan Academy of Bioresource Utilization, Beijing 100102; \\ ${ }^{4}$ Gaubau Kender (Aletai, Xinjiang) Limited Company, Aletai 836500, P.R. China
}

Received August 20, 2015; Accepted October 6, 2015

DOI: 10.3892/or.2016.4682

\begin{abstract}
High levels of fatty acid synthase (FAS) expression have been found in many tumors, including prostate, breast, and ovarian cancers, and inhibition of FAS has been reported to obstruct tumor growth in vitro and in vivo. Curcumin is one of the major active ingredients of Curcuma longa, which has been proven to inhibit the growth of cancer cells. In the present study, we investigated the potential activity of curcumin as a FAS inhibitor for chemoprevention of breast cancer. As a result, curcumin induced human breast cancer MDA-MB-231 cell apoptosis with the half-inhibitory concentration value of $3.63 \pm 0.26 \mu \mathrm{g} / \mathrm{ml}$, and blocked FAS activity, expression and mRNA level in a dose-dependent manner. Curcumin also regulated B-cell lymphoma $2(\mathrm{Bcl}-2)$, Bax and p-Akt protein expression in MDA-MB-231 cells. Moreover, FAS knockdown showed similar effect as curcumin. All these results suggested that curcumin may induce cell apoptosis via inhibiting FAS.
\end{abstract}

\section{Introduction}

Fatty acid synthase (EC 2.3.1.85, ab. FAS) is a key metabolic enzyme which catalyzing the de novo synthesis of long

Correspondence to: Dr Xiaofeng Ma, College of Life Sciences, University of Chinese Academy of Sciences, 19A Yuquan Road, Beijing 100049, P.R. China

E-mail: maxiaofeng@ucas.ac.cn

Abbreviations: Ac-CoA, acetyl CoA; DMEM, Dulbecco's modified Eagle's medium; DMSO, dimethyl sulfoxide; EGCG, epigallocatechin gallate; FAS, fatty acid synthase; FBS, fetal bovine serum; $\mathrm{IC}_{50}$, half-inhibitory concentration; Mal-CoA, malonyl-CoA; MAT, malonyl/acetyltransferase; MTT, 3-4,5-dimethylthiazol-2-yl2,3-diphenyltetrazolium bromide; NADPH, nicotinamide adenine dinucleotide phosphate; PBS, phosphate-buffered saline

Key words: curcumin, fatty acid synthase, inhibitor, breast cancer, MDA-MB-231 cells, apoptosis chain saturated fatty acids from acetyl-CoA (Ac-CoA) and malonyl-CoA (Mal-CoA) in the presence of the reducing substrate nicotinamide adenine dinucleotide phosphate (NADPH) (1). Most human tissues, except liver and adipose tissue, exhibit low expression of FAS. However, the expression of FAS is especially high in a variety of common human cancers (2-5). It has been reported that many FAS inhibitors, such as cerulenin, C75, orlistat and epigallocatechin gallate (EGCG), have joint weight-loss and antitumor effects (6-9). Therefore, FAS may be a dual therapeutic target for treating both obesity and cancer.

Curcumin (Fig. 1), a hydrophobic polyphenol derived from the rhizome of Curcuma longa, possesses wide pharmacological activities including respiratory conditions, inflammation, breast disorders, diabetic wounds, and certain tumors (10). Curcumin induces cell death in some cancers, such as gastric and colon cancers (11), human melanoma (12), and lung cancer (13) without major cytotoxic effects on healthy cells (14-16). However, the mechanism involved is not fully understood.

In our previous study, we found curcumin to show both fast-binding and slow-binding inhibition to FAS with a halfinhibitory concentration $\left(\mathrm{IC}_{50}\right)$ value of $10.5 \mu \mathrm{g} / \mathrm{ml}(17)$. Compared with EGCG and cerulenin, two classical FAS inhibitors, curcumin showed stronger inhibitory activity. In the present study, we investigated the effect of curcumin on FAS overexpressed human breast cancer cells. We demonstrated that curcumin inhibited FAS activity and expression in MDA-MB-231 cells. Curcumin also regulated pro-apoptotic and anti-apoptotic proteins such as Bax, B-cell lymphoma 2 (Bcl-2), Akt, phosphorylate-Akt (p-Akt) expression in a dose-dependent manner.

\section{Materials and methods}

Reagents. Ac-CoA, Mal-CoA, NADPH, DMSO, Hoechst 33258 and curcumin were purchased from Sigma-Aldrich (St. Louis, MO, USA). Dulbecco's modified Eagle's medium (DMEM) and fetal bovine serum (FBS) were purchased from Gibco-BRL (Beijing, China). FAS antibody for immunoblotting was obtained from BD Biosciences Pharmingen 
(Shanghai, China). GAPDH antibody was purchased from Cell Signaling Technology, Inc. (Shanghai, China). 3-4,5-dimethylthiazol-2-yl-2,3-diphenyltetrazolium bromide (MTT), phosphate-buffered saline (PBS) and the TRIzol reagent were purchased from Invitrogen (Beijing, China). Annexin V-FITC/PI apoptosis detection kit was purchased from Mbchem (Shanghai, China). The PCR primers for human $\beta$-actin and FAS were synthesized by SBS Genetech Co., Ltd. (Beijing, China). M-MLV, Rnasin and Oligo (dT) were purchased from Promega (Beijing, China). ECL and PVDF membrane were obtained from Millipore (Beijing, China).

Cell viability assay. Tests were performed in 96-well plates. MDA-MB-231 cells were cultured in the plates until confluence, cells were incubated with either DMSO $(1: 1,000)$ or increasing concentrations of curcumin for $24 \mathrm{~h}\left(37^{\circ} \mathrm{C}, 5 \%\right.$ $\mathrm{CO}_{2}$ ). The medium was then changed to a fresh one with $0.5 \mathrm{mg} / \mathrm{ml} \mathrm{MTT}$. After $4 \mathrm{~h}$ of incubation at $37^{\circ} \mathrm{C}$, the plates were again decanted, and $150 \mu \mathrm{l}$ of DMSO was added to solubilize the formazan crystals present in viable cells. The plate was analyzed by spectrometry at the wavelength of $492 \mathrm{~nm}$ by a microplate spectrophotometer (Multiskan, MK3). Data were obtained from the average of five wells, and the assay was repeated three times.

Immunoblot analysis. Cells were washed three times with ice-cold PBS and harvested in RIPA lysis buffer with $1 \mathrm{mM}$ PMSF, and then lysed on ice for $5 \mathrm{~min}$. The homogenate was centrifuged at $12,000 \mathrm{rpm}$ for $30 \mathrm{~min}$ at $4^{\circ} \mathrm{C}$ and supernatant was collected for FAS analysis. Equal protein extracts were separated by SDS-PAGE, then electrophoretically transferred to PVDF membranes. Incubation with primary and secondary antibodies was performed in Tris-buffered saline containing 5\% non-fat dry milk for $2 \mathrm{~h}$ or more. After incubation, membranes were washed in Tris-buffered saline containing $0.1 \%$ Tween-20. ECL was used for detection. Blots were reprobed with an antibody against GAPDH as a loading control of protein loading and transfer.

RNA isolation and RT-PCR analysis. Total RNA was extracted with TRIzol reagent according to the manufacturer's instructions and reverse-transcribed by RiboClone $\mathrm{M}-\mathrm{MLV}\left(\mathrm{H}^{-}\right)$ cDNA technology. The synthesized single-stranded cDNA was used for amplification of a specific target. The $\beta$-actin gene was amplified as a loading control. The PCR conditions were denatured at $95^{\circ} \mathrm{C}$ for $5 \mathrm{~min}$ and followed by 30 cycles $\left(95^{\circ} \mathrm{C}, 15 \mathrm{sec}, 55^{\circ} \mathrm{C}, 15 \mathrm{sec}, 72^{\circ} \mathrm{C}, 30 \mathrm{sec}\right)$. The primer sequences were as follows: FAS forward, 5'-AGATCCTGGAACGAGAA CACGAT-3' and reverse, 5'-GAGACGTGTCACTCCTGGAC TTG-3'; and $\beta$-actin forward, 5'-GTGGGCCGCTCTAGGCA CCAA-3' and reverse, 5'-CTCTTTGATGTCACGACGAT TTC-3'.

The amplified products were visualized on $1 \%$ agarose gels. Quantification was performed in duplicate and the experiments were repeated independently three times. We used ImageJ software to analyze the results of gels.

Cell FAS activity assay. FAS activity in cells was assessed in a routine manner with some modifications. In brief, after cells were harvested, pelleted by centrifugation, resuspended

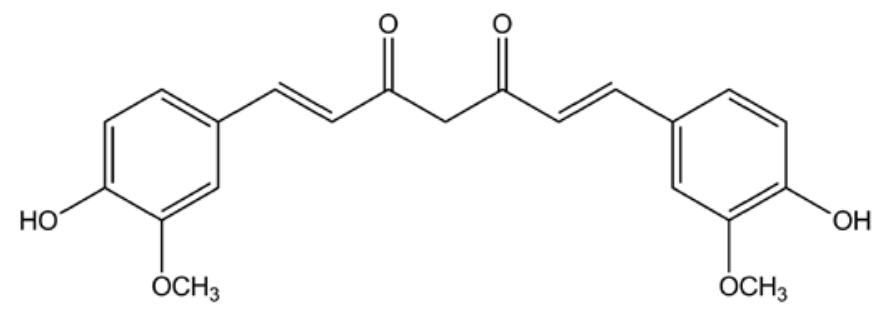

Figure 1. Chemical structure of curcumin.

in cold assay buffer (100 $\mathrm{mM}$ potassium phosphate buffer, $1 \mathrm{mM}$ EDTA, $1 \mathrm{mM}$ PMSF and $1 \mathrm{mM}$ dithiolthreitol, $\mathrm{pH}$ 7.0), ultrasonically disrupted and centrifuged at $12,000 \mathrm{rpm}$ for $30 \mathrm{~min}$ at $4^{\circ} \mathrm{C}$, the supernatant was collected for the overall reaction assay. Fifty microliters of supernatant was added to the reaction mix contained $25 \mathrm{mM} \mathrm{KH} \mathrm{PO}_{4}-\mathrm{K}_{2} \mathrm{HPO}_{4}$ buffer, $0.25 \mathrm{mM}$ EDTA, $0.25 \mathrm{mM}$ dithiothreitol, $30 \mu \mathrm{M}$ Ac-CoA, $100 \mu \mathrm{M}$ Mal-CoA, $350 \mu \mathrm{M}$ NADPH (pH 7.0) in a total volume of $200 \mu \mathrm{l}$. Protein content in the supernatant was determined using a bicinchoninic acid (BCA) assay (Pierce) and results were expressed as the specific activity of FAS $(\mathrm{U} / \mathrm{mg})$.

Hoechst 33258 staining. MDA-MB-231 cells were seeded on 24-well culture dishes and cultured in the plates until confluence. Cells were treated with indicated dose of curcumin. After $24 \mathrm{~h}$ incubated in $37^{\circ} \mathrm{C}, 5 \% \mathrm{CO}_{2}$ incubator, the medium was changed to a fresh one with $0.5 \mu \mathrm{g} / \mathrm{ml}$ Hoechst 33258 and the dish was incubated in an incubator for $30 \mathrm{~min}$, then the cells were washed three times with PBS. Nuclear staining was examined under the fluorescence microscope and images were captured using ImagePro Plus software (Media Cybernetics, Silver Spring, MD, USA).

Annexin V/propidium iodide (PI) dual staining. MDA-MB-231 cells were treated with indicated concentrations of curcumin. Then cells were harvested, and the percentage of cells undergoing apoptosis was measured by fluorescence microscopy after staining with fluorescein-conjugated Annexin V and PI staining $5 \mathrm{~min}$ in the dark.

RNA interference. MDA-MB-231 cells were transiently transfected with a small interfering RNA (siRNA) that silences expression of FAS. The FAS-targeted siRNAs (sense, CCCUG AGAUCCCAGCGCUGdTdT and antisense, CAGCGCUGGG AUCUCAGGGdTdT) were synthesized by Invitrogen. For transient expression, cell lines were transfected by using Lipofectamine 2000 reagent (Invitrogen) according to the manufacturer's instructions. After incubating the cells for $6 \mathrm{~h}$, the lipid and siRNA complex was removed, and fresh growth medium was added. Cells were lysed $24 \mathrm{~h}$ after transfection, and specific protein levels were determined by western blot analysis with specific antibodies against the targeted proteins and GAPDH as control.

\section{Results}

Effect of curcumin on the viability of MDA-MB-231 cells. The anti-viability effect of curcumin on MDA-MB-231 cells was 


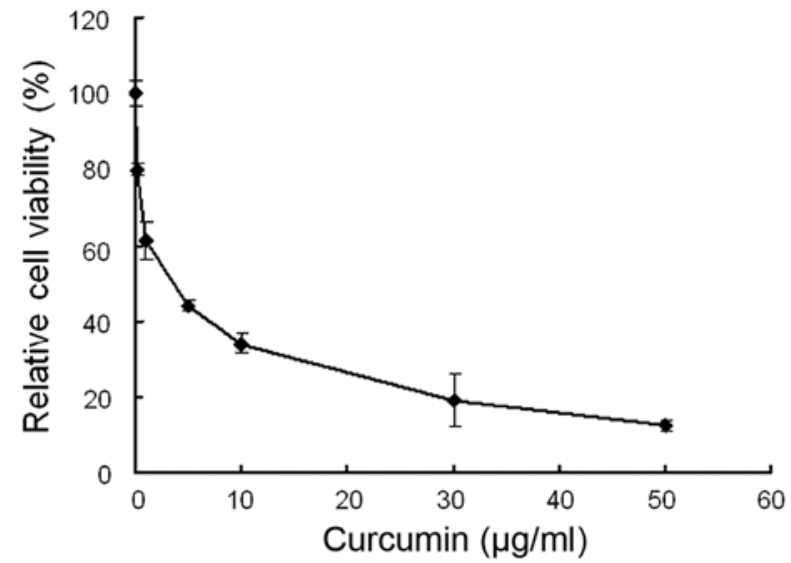

Figure 2. Dose-dependent inhibitory effects of curcumin on cell viability of MDA-MB-231 cells. Cell viability was determined by MTT assay. MDA-MB-231 cells were incubated with curcumin for $24 \mathrm{~h}$ at the concentrations $0-50 \mu \mathrm{g} / \mathrm{ml}$. $\mathrm{IC}_{50}=3.63 \pm 0.26 \mu \mathrm{g} / \mathrm{ml}$. Bars represent means $\pm \mathrm{SD}$.

examined by MTT assay. Following treatment with $0-50 \mu \mathrm{g} / \mathrm{ml}$ curcumin, cell viability was significantly decreased. As shown in Fig. 2, curcumin reduced cell viability in a dose-dependent manner with an $\mathrm{IC}_{50}$ value of $3.63 \pm 0.26 \mu \mathrm{g} / \mathrm{ml}$.

Curcumin induces MDA-MB-231 cells apoptosis. According to the results of MTT assay, the apoptotic effect of curcumin $(0,5,10$ and $15 \mu \mathrm{g} / \mathrm{ml})$ on MDA-MB-231 cells was examined by using Hoechst 33258 staining and the Annexin V/PI dual staining. After exposure to four concentrations of curcumin for $24 \mathrm{~h}$, apoptotic MDA-MB-231 cells were demonstrated by the result of Hoechst 33258 staining, which revealed a cell membrane permeability increase and nuclear condensation (Fig. 3), and by Annexin V/PI dual staining, where cells were observed to be Annexin V-FITC- and PI-positive, indicating that they were in end-stage apoptosis or already dead (Fig. 4).

Curcumin downregulated FAS expression and inhibited FAS activity in MDA-MB-231 cells. Curcumin has been reported to be a highly active FAS inhibitor, however, no previous studies focused on the activity of curcumin on intracellular FAS activity in breast cancer cells. Therefore, we measured the effects of curcumin on the expression and activity of FAS in MDA-MB-231 cells. As shown in Fig. 5, compared with control, the cells treated with curcumin showed much lower expression level of FAS. Compared with control, curcumin showed a dose-dependent inhibition on FAS activity. As shown in Fig. 6 , the relative activities of FAS were reduced by $6.8 \%$ at $5 \mu \mathrm{g} / \mathrm{ml}, 41.1 \%$ at $10 \mu \mathrm{g} / \mathrm{ml}$ and $59.7 \%$ at $15 \mu \mathrm{g} / \mathrm{ml}$. These results indicated that curcumin potently inhibits FAS activity in this breast cancer cell line.

Effects of curcumin on FAS mRNA levels in MDA-MB-231 cells. To further explore the mechanism underlying the suppression of cancer cells by curcumin, the mRNA level of FAS was also examined. As shown in Fig. 7, compared with control, curcumin treated cells showed significantly lower mRNA levels of FAS.

Effects of curcumin on Bax and Bcl-2 proteins. Bax is a pro-apoptotic protein and plays a key role in mitochondrial stress-induced cell apoptosis. Increased levels of Bax could promote cells apoptosis. Bcl-2 is an anti-apoptotic protein that can inhibit apoptosis induced by cytochrome $c$ release. Decreased Bcl-2 protein levels may lead to cell apoptosis. As shown in Fig. 5, after curcumin administration, the expression level of Bax showed a dose-dependent increase. In contrast, curcumin decreased Bcl-2 expression in a dose-dependent manner.

Curcumin upregulated Akt phosphorylation in MDA-MB-231 cells. The activity of curcumin on Akt was also determined. After treated with $0,5,10$ and $15 \mu \mathrm{g} / \mathrm{ml}$ curcumin for $24 \mathrm{~h}$, MDA-MB-231 cells were collected and cell lysates were subjected to western blot analysis for phospho-Akt. The result in Fig. 5 showed that curcumin increased the phosphorylation of Akt at Ser473 in a dose-dependent manner, without affecting total Akt expression.

Effect of siRNA mediated FAS silencing on MDA-MB-231 cells. Because overexpression of FAS protected immortalized cancer cells from apoptosis, we wanted to assess the effect of short interfering RNA to FAS on apoptosis in MDA-MB-231 cells. To accomplish this, MDA-MB-231 cells were transfected with FAS siRNA $(0,200,300$ and $500 \mathrm{nM})$, then the expression levels of FAS, Akt, Bcl-2 were measured $48 \mathrm{~h}$ after transfection by western blotting. As shown in Fig. 8, compared

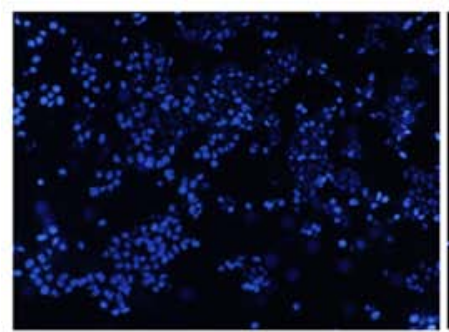

0

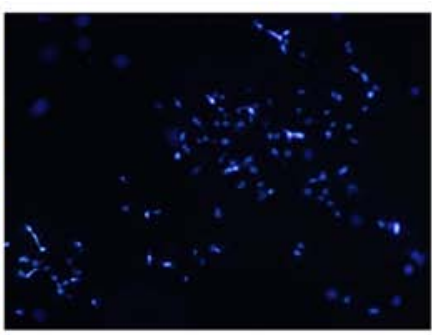

5

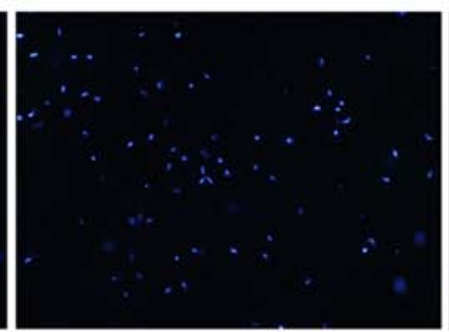

10

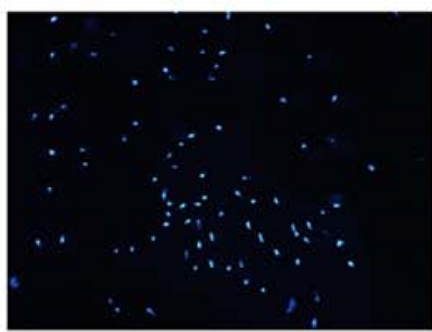

15

$\operatorname{curcumin}(\mu \mathrm{g} / \mathrm{ml})$

Figure 3. Hoechst 33258 staining in curcumin treated MDA-MB-231 cells. Cell culture was performed as described in Materials and methods. Images of MDA-MB-231 cells were taken after Hoechst 33258 staining, the concentrations of curcumin were: $0,5,10$ and $15 \mu \mathrm{g} / \mathrm{ml}$. Original magnification, $\mathrm{x} 200$. 

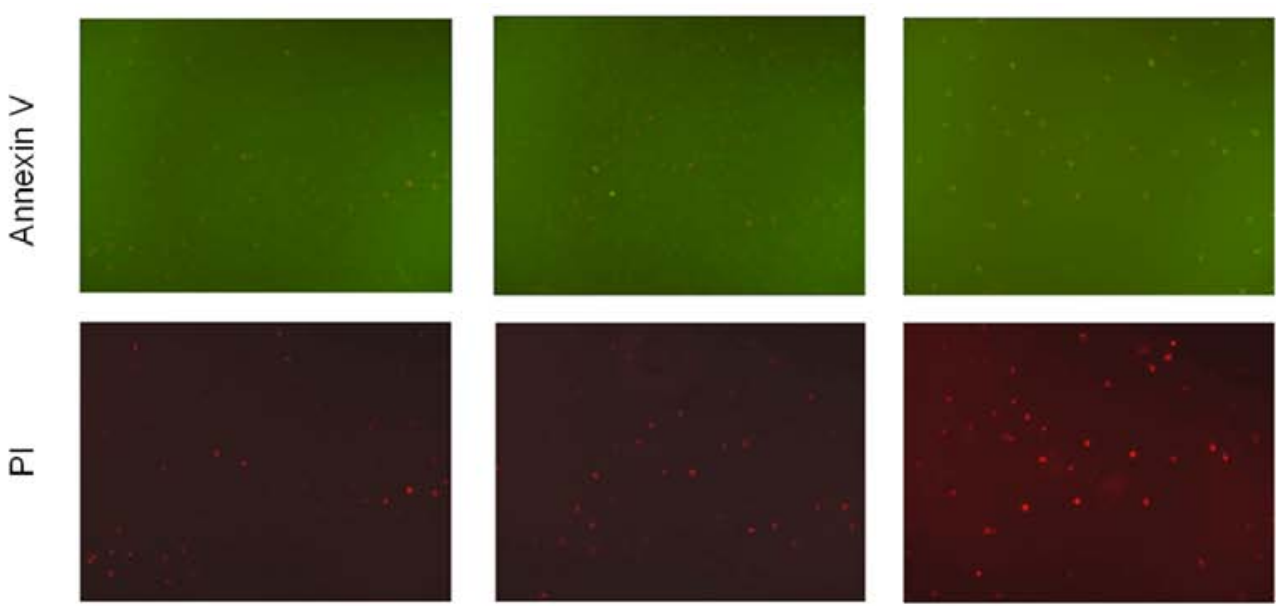

5

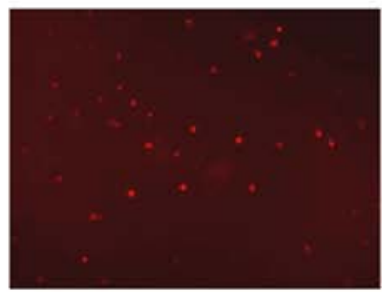

10
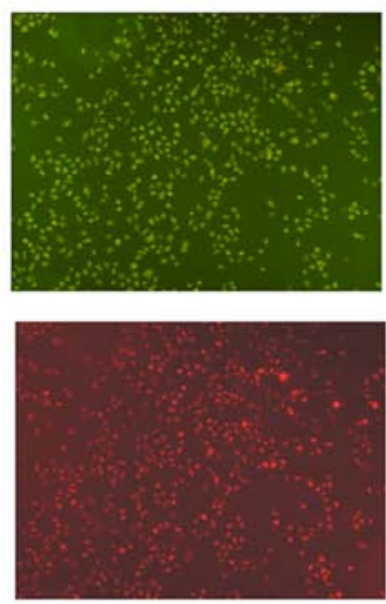

15

Figure 4. Annexin V/PI dual staining in curcumin treated MDA-MB-231 cells. Cell culture was performed as described in Materials and methods. Images of MDA-MB-231 cells were taken after Annexin V and PI dual staining, the concentrations of curcumin were: $0,5,10$ and $15 \mu \mathrm{g} / \mathrm{ml}$. Original magnification, $\mathrm{x} 200$.

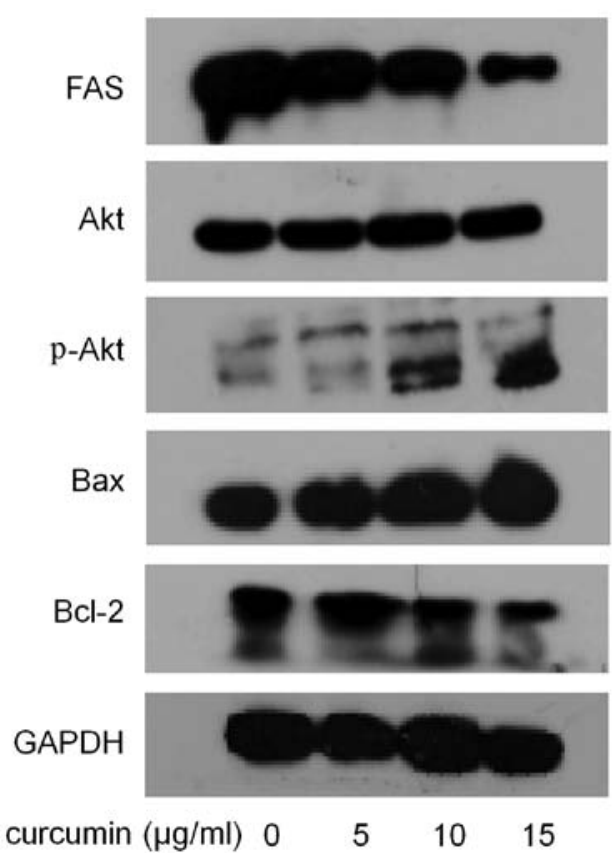

Figure 5. Regulation of curcumin on the expression levels of FAS, Akt, p-Akt, Bax, and Bcl-2 in MDA-MB-231 cells. Representative western blots showing a dose-dependent inhibition of FAS, Bcl-2 expression levels but upregulating the expression levels of p-Akt, Bax in MDA-MB-231 cells after treating with curcumin at $24 \mathrm{~h}$.

with the control, the cells treated with siRNA showed much lower level of FAS. Reduction of Bcl-2 expression showed a dose-dependent manner with increase of siRNA, but total Akt expression had no change.

\section{Discussion}

FAS is a key enzyme catalyzing the synthesis of long-chain fatty acids from small molecule carbon unit in vivo. According to the biochemical and pharmacological studies in recent years, FAS is believed to be a dual target of treating both obesity and

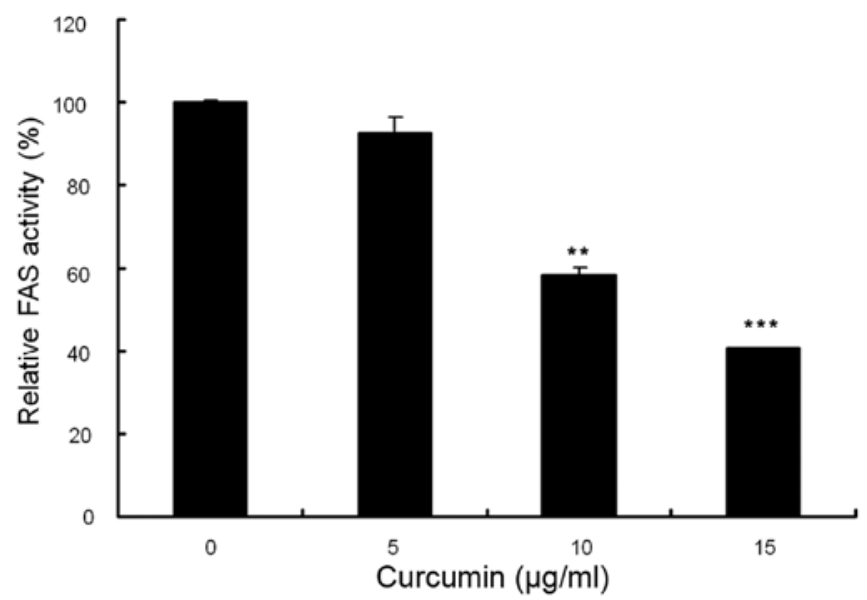

Figure 6. Inhibitory effects of curcumin on FAS activities in MDA-MB-231 cells. The dose-dependent inhibition of FAS by curcumin at the concentrations of $0,5,10$ and $15 \mu \mathrm{g} / \mathrm{ml}$ was measured. Values represent the mean $\pm \mathrm{SD}$ of triplicate determinations. ${ }^{* *} \mathrm{P}<0.01$ compared to control; ${ }^{* * *} \mathrm{P}<0.001$ compared to control.

cancer $(18,19)$. Fatty acid biosynthesis is dependent on FAS to satisfy the needs of cell division and proliferation. FAS expression level in cancer cells is much higher than that of normal tissue cells (20). There is a correlation between expression and prognosis in malignant tumors (21). RNAi knockdown experiments have shown that multiple cancer cell lines depend on FAS for proliferation and survival (22). FAS appears to play a key role in tumor initiation and propagation for many malignancies and represents an attractive target for cancer treatment. Inhibition of FAS has emerged as a promising therapeutic target in cancer, and numerous inhibitors have been investigated $(19,21)$. However, severe pharmacological limitations have challenged their clinical testing.

Curcumin is a phenolic pigment extracted from Curcuma longa, which is an effective anti-mutagenic and anticancer agent. In Chinese medicine, Curcuma longa has long been used as a medicinal plant (23). Numerous studies have suggested 


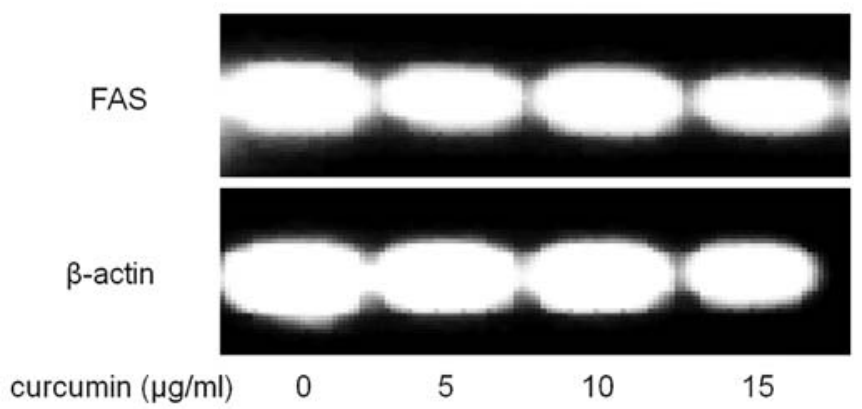

Figure 7. Effect of curcumin on FAS mRNA. MDA-MB-231 cells were treated with $0,5,10$ and $15 \mu \mathrm{g} / \mathrm{ml}$ curcumin. After $24 \mathrm{~h}$, mRNA was extracted and quantified via RT-PCR, and normalized to $\beta$-actin mRNA. Data were normalized to control cells without curcumin $(0 \mu \mathrm{g} / \mathrm{ml})$.

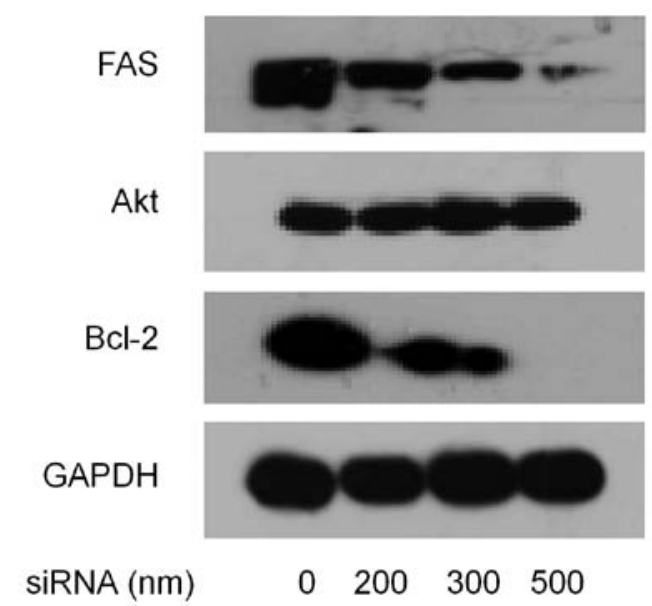

Figure 8. Regulation of siRNA on the expression levels of FAS, Akt, and Bcl-2 in MDA-MB-231 cells. MDA-MB-231 cells transfected with siRNA-targeting FAS or with the control were subjected to immunoblotting analyses with antibodies against FAS, Akt, Bcl-2, and GAPDH.

that curcumin can inhibit the proliferation of cancer cells and promote cancer cells apoptosis $(24,25)$. Yet, little is known about its mechanism that inhibits the growth of cancer cells.

Since curcumin is a highly active FAS inhibitor, this study is focus on the relationship between the apoptotic effect and FAS inhibitory effect of curcumin. We found that treatment with curcumin produced a dose-dependent decrease in the viability of MDA-MB-231 cells. Hoechst 33258 staining, and the Annexin V/PI dual staining results indicated that curcumin induced apoptosis dose-dependently (Figs. 3 and 4). After treating with curcumin, the mRNA, expression level, as well as activity of FAS were also decreased in a dose-dependent manner (Figs. 5-7). These results indicated that curcumin potently blocked FAS in MDA-MB-231 cells.

Cell death signaling frequently converges on mitochondria, which is controlled by the activities of pro- and anti-apoptotic Bcl-2 family proteins (26-31). In the present study, we found that curcumin treatment decreased anti-apoptotic Bcl-2 and increased pro-apoptotic Bax proteins, thereby causing a significant increase in the Bax/Bcl-2 ratio in MDA-MB-231 cells. In addition, FAS siRNA also downregulated the expression level of Bcl-2. These results indicated that bcl-2 family was involved in curcumin-induced apoptosis.
The activation of Akt is one of the most frequent alterations observed in human cancer cells (32-34). Inhibition of FAS activity preferentially inhibits cell growth and induces apoptosis in a number of cancel cells (35). Considerable evidence demonstrates that phosphatidylinositol 3-kinase (PI3K)/Akt signaling plays an important role in cancer progression and has been linked with FAS expression in cancer cells $(36,37)$. In the present study, to assess whether the activity of Akt was affected by curcumin, we explored the phosphorylation of Akt in MDA-MB-231 cells after treatment with curcumin and FAS siRNA. The results showed that p-Akt was noticeably increased when treated with curcumin in MDA-MB-231 cells. However, expression levels of Akt phosphorylation were not detected in MDA-MB-231 cells exposed to increasing concentrations of FAS siRNA. Moreover, the total levels of the corresponding Akt were not altered in either curcumin or siRNA treated breast cancer cells. These results demonstrated that PI3K/AKT signaling pathway may be involved in curcumin-induced apoptosis, but the detailed mechanisms involved are not fully understood.

In conclusion, curcumin was able to induce MDA-MB-231 cell apoptosis via inhibiting intracellular FAS activity and downregulating FAS expression and mRNA level. FAS inhibition plays a great role in curcumin regulated signal proteins including Bax, Bcl-2, Akt and p-Akt. FAS knockdown by siRNA also illustrated that FAS inhibition closely related to cell apoptosis. These results support the important role of FAS in MDA-MB-231 cells and suggest that FAS is the target that curcumin act on. Our findings combined with its well-documented pharmacological safety profile make curcumin a promising drug candidate for the treatment of breast cancer.

\section{Acknowledgements}

The present study was supported by the Fusion of Science and Education Special Fund, College of Life Sciences, University of Chinese Academy of Sciences (KJRH2015-012); Application Basic Research Project of Qinghai Province (2015-ZJ-728); Youth Innovation Promotion Association, CAS; 2014 Youth National Natural Science Foundation of China (no. 31300292); The Key Program of 'The Dawn of West China' Talent Foundation of CAS (2012); 2014 Youth National Natural Science Foundation of China (no. 31300292); The Key Program of 'The Dawn of West China' Talent Foundation of CAS (2012), as well as High-Tech Research and Development Program of Xinjiang (no. 201315108) and China Postdoctoral Science Foundation (no. 2013M540785).

\section{References}

1. Menendez JA and Lupu R: Fatty acid synthase and the lipogenic phenotype in cancer pathogenesis. Nat Rev Cancer 7: 763-777, 2007.

2. Alò PL, Visca P, Trombetta G, Mangoni A, Lenti L, Monaco S, Botti C, Serpieri DE and Di Tondo U: Fatty acid synthase (FAS) predictive strength in poorly differentiated early breast carcinomas. Tumori 85: 35-40, 1999.

3. Shurbaji MS, Kalbfleisch JH and Thurmond TS: Immunohistochemical detection of a fatty acid synthase (OA-519) as a predictor of progression of prostate cancer. Hum Pathol 27: 917-921, 1996.

4. Gansler TS, Hardman W III, Hunt DA, Schaffel S and Hennigar RA: Increased expression of fatty acid synthase (OA-519) in ovarian neoplasms predicts shorter survival. Hum Pathol 28: 686-692, 1997. 
5. Visca P, Sebastiani V, Botti C, Diodoro MG, Lasagni RP, Romagnoli F, Brenna A, De Joannon BC, Donnorso RP, Lombardi G, et al: Fatty acid synthase (FAS) is a marker of increased risk of recurrence in lung carcinoma. Anticancer Res 24: 4169-4173, 2004.

6. Mashima T, Seimiya $\mathrm{H}$ and Tsuruo T: De novo fatty-acid synthesis and related pathways as molecular targets for cancer therapy. Br J Cancer 100: 1369-1372, 2009.

7. Knowles LM, Yang C, Osterman A and Smith JW: Inhibition of fatty-acid synthase induces caspase-8-mediated tumor cell apoptosis by up-regulating DDIT4. J Biol Chem 283: 31378-31384, 2008.

8. Brusselmans K, De Schrijver E, Heyns W, Verhoeven G and Swinnen JV: Epigallocatechin-3-gallate is a potent natural inhibitor of fatty acid synthase in intact cells and selectively induces apoptosis in prostate cancer cells. Int J Cancer 106: $856-862,2003$

9. Puig T, Vázquez-Martín A, Relat J, Pétriz J, Menéndez JA, Porta R, Casals G, Marrero PF, Haro D, Brunet J, et al: Fatty acid metabolism in breast cancer cells: Differential inhibitory effects of epigallocatechin gallate (EGCG) and C75. Breast Cancer Res Treat 109: 471-479, 2008.

10. Ruby AJ, Kuttan G, Babu KD, Rajasekharan KN and Kuttan R: Anti-tumour and antioxidant activity of natural curcuminoids. Cancer Lett 94: 79-83, 1995

11. Moragoda L, Jaszewski R and Majumdar AP: Curcumin induced modulation of cell cycle and apoptosis in gastric and colon cancer cells. Anticancer Res 21: 873-878, 2001.

12. Bush JA, Cheung KJ Jr and Li G: Curcumin induces apoptosis in human melanoma cells through a Fas receptor/caspase-8 pathway independent of p53. Exp Cell Res 271: 305-314, 2001.

13. Radhakrishna Pillai G, Srivastava AS, Hassanein TI, Chauhan DP and Carrier E: Induction of apoptosis in human lung cancer cells by curcumin. Cancer Lett 208: 163-170, 2004.

14. Chainani-Wu N: Safety and anti-inflammatory activity of curcumin: A component of tumeric (Curcuma longa). J Altern Complement Med 9: 161-168, 2003.

15. Syng-Ai C, Kumari AL and Khar A: Effect of curcumin on normal and tumor cells: Role of glutathione and bcl-2. Mol Cancer Ther 3: 1101-1108, 2004.

16. Anand P, Sundaram C, Jhurani S, Kunnumakkara AB and Aggarwal BB: Curcumin and cancer: An 'old-age' disease with an 'age-old' solution. Cancer Lett 267: 133-164, 2008.

17. Zhao J, Sun XB, Ye F and Tian WX: Suppression of fatty acid synthase, differentiation and lipid accumulation in adipocytes by curcumin. Mol Cell Biochem 351: 19-28, 2011.

18. Milgraum LZ, Witters LA, Pasternack GR and Kuhajda FP: Enzymes of the fatty acid synthesis pathway are highly expressed in in situ breast carcinoma. Clin Cancer Res 3: 2115-2120, 1997.

19. Kuhajda FP: Fatty acid synthase and cancer: New application of an old pathway. Cancer Res 66: 5977-5980, 2006.

20. Pizer ES, Wood FD, Heine HS, Romantsev FE, Pasternack GR and Kuhajda FP: Inhibition of fatty acid synthesis delays disease progression in a xenograft model of ovarian cancer. Cancer Res 56: 1189-1193, 1996.

21. Kuhajda FP: Fatty-acid synthase and human cancer: New perspectives on its role in tumor biology. Nutrition 16: 202-208, 2000 .
22. Flavin R, Peluso S, Nguyen PL and Loda M: Fatty acid synthase as a potential therapeutic target in cancer. Future Oncol 6: 551-562, 2010.

23. Hatcher H, Planalp R, Cho J, Torti FM and Torti SV: Curcumin: From ancient medicine to current clinical trials. Cell Mol Life Sci 65: 1631-1652, 2008

24. Hermine O, Haioun C, Lepage E, d'Agay MF, Briere J, Lavignac C, Fillet G, Salles G, Marolleau JP, Diebold J, et al: Prognostic significance of bcl-2 protein expression in aggressive non-Hodgkin's lymphoma. Groupe d'Etude des Lymphomes de l'Adulte (GELA). Blood 87: 265-272, 1996.

25. Anto RJ, Maliekal TT and Karunagaran D: L-929 cells harboring ectopically expressed RelA resist curcumin-induced apoptosis. J Biol Chem 275: 15601-15604, 2000.

26. Doglioni C, Dei Tos AP, Laurino L, Chiarelli C, Barbareschi M and Viale G: The prevalence of BCL-2 immunoreactivity in breast carcinomas and its clinicopathological correlates, with particular reference to oestrogen receptor status. Virchows Arch 424: 47-51, 1994.

27. Onodera J, Nakamura S, Nagano I, Tobita M, Yoshioka M, Takeda A, Oouchi $\mathrm{M}$ and Itoyama Y: Upregulation of Bcl-2 protein in the myasthenic thymus. Ann Neurol 39: 521-528, 1996.

28. Salakou S, Tsamandas AC, Bonikos DS, Papapetropoulos T and Dougenis D: The potential role of bcl-2, bax, and Ki67 expression in thymus of patients with myasthenia gravis, and their correlation with clinicopathologic parameters. Eur J Cardiothorac Surg 20: 712-721, 2001.

29. Oltvai ZN, Milliman CL and Korsmeyer SJ: Bcl-2 heterodimerizes in vivo with a conserved homolog, Bax, that accelerates programmed cell death. Cell 74: 609-619, 1993.

30. Yang E and Korsmeyer SJ: Molecular thanatopsis: A discourse on the BCL2 family and cell death. Blood 88: 386-401, 1996.

31. Korsmeyer SJ: BCL-2 gene family and the regulation of programmed cell death. Cancer Res 59 (Suppl 7): 1693s-1700s, 1999.

32. Testa JR and Bellacosa A: AKT plays a central role in tumorigenesis. Proc Natl Acad Sci USA 98: 10983-10985, 2001.

33. Vivanco I and Sawyers CL: The phosphatidylinositol 3-kinase AKT pathway in human cancer. Nat Rev Cancer 2: 489-501, 2002.

34. Li S, Zhou Y, Wang R, Zhang H, Dong Y and Ip C: Selenium sensitizes MCF-7 breast cancer cells to doxorubicin-induced apoptosis through modulation of phospho-Akt and its downstream substrates. Mol Cancer Ther 6: 1031-1038, 2007.

35. Pizer ES, ChrestFJ, DiGiuseppe JA and Han WF: Pharmacological inhibitors of mammalian fatty acid synthase suppress DNA replication and induce apoptosis in tumor cell lines. Cancer Res 58: 4611-4615, 1998.

36. De Schrijver E, Brusselmans K, Heyns W, Verhoeven G and Swinnen JV: RNA interference-mediated silencing of the fatty acid synthase gene attenuates growth and induces morphological changes and apoptosis of LNCaP prostate cancer cells. Cancer Res 63: 3799-3804, 2003

37. Wang HQ, Altomare DA, Skele KL, Poulikakos PI, Kuhajda FP, Di Cristofano A and Testa JR: Positive feedback regulation between AKT activation and fatty acid synthase expression in ovarian carcinoma cells. Oncogene 24: 3574-3582, 2005. 